\title{
Aerobic Soil Biotransformation of 6:2 Fluorotelomer lodide
}

\author{
Ting Ruan, ${ }^{\dagger}$ Bogdan Szostek, ${ }^{\ddagger}$ Patrick W. Folsom, ${ }^{\ddagger}$ Barry W. Wolstenholme, ${ }^{\ddagger}$ Runzeng Liu, ${ }^{\dagger}$ Jiyan Liu, ${ }^{\dagger}$ \\ Guibin Jiang, ${ }^{* \dagger}$ Ning Wang, ${ }^{*}+\frac{+}{+}$ and Robert C. Buck ${ }^{*}$ \\ ${ }^{\dagger}$ State Key Laboratory of Environmental Chemistry and Ecotoxicology, Research Center for Eco-Environmental Sciences, Chinese \\ Academy of Sciences, Post Office Box 2871, Beijing 100085, People's Republic of China \\ ${ }^{\ddagger}$ DuPont Haskell Global Centers for Health and Environmental Sciences, E. I. du Pont de Nemours and Company, Incorporated, \\ Glasgow 300, Post Office Box 6300, Newark, Delaware 19714-6300, United States
}

Supporting Information

ABSTRACT: $6: 2$ FTI $\left[\mathrm{F}\left(\mathrm{CF}_{2}\right)_{6} \mathrm{CH}_{2} \mathrm{CH}_{2} \mathrm{I}\right]$ is a principal industrial raw material used to manufacture $6: 2 \mathrm{FTOH}$ $\left[\mathrm{F}\left(\mathrm{CF}_{2}\right)_{6} \mathrm{CH}_{2} \mathrm{CH}_{2} \mathrm{OH}\right]$ and 6:2 FTOH-based products and could enter aerobic environments from possible industrial emissions where it is manufactured. This is the first study to assess 6:2 FTI aerobic soil biotransformation, quantify transformation products, and elucidate its biotransformation pathways. 6:2 FTI biotransformation led to 6:2 FTOH as a key intermediate, which was subsequently biotransformed to other significant transformation products, including PFPeA [F$\left(\mathrm{CF}_{2}\right)_{4} \mathrm{COOH}, 20 \mathrm{~mol} \%$ at day 91], 5:3 acid [F$\left.\left(\mathrm{CF}_{2}\right)_{5} \mathrm{CH}_{2} \mathrm{CH}_{2} \mathrm{COOH}, 16 \mathrm{~mol} \%\right]$, PFHxA $\left[\mathrm{F}\left(\mathrm{CF}_{2}\right)_{5} \mathrm{COOH}\right.$, $3.8 \mathrm{~mol} \mathrm{\%}]$, and $4: 3$ acid $\left[\mathrm{F}\left(\mathrm{CF}_{2}\right){ }_{4} \mathrm{CH}_{2} \mathrm{CH}_{2} \mathrm{COOH}, 3.0 \mathrm{~mol} \%\right]$ PFHpA $\left[\mathrm{F}\left(\mathrm{CF}_{2}\right)_{6} \mathrm{COOH}, 16 \mathrm{~mol} \%\right.$ at day 91], perhaps via another putative intermediate, 6:2 $\mathrm{FTUI}\left[\mathrm{F}(\mathrm{CF})_{6} \mathrm{CH}=\mathrm{CHI}\right]$, whose molecular identity and further biotransformation were not verified because of the lack of an authentic standard. Total recovery of the aforementioned per- and polyfluorocarboxylates accounted for $59 \mathrm{~mol} \%$ of initially applied 6:2 FTI by day 91 , in comparison to $56 \mathrm{~mol} \%$ when soil was dosed with $6: 2 \mathrm{FTOH}$, which did not lead to PFHpA. Thus, were 6:2 FTI to be released from its manufacture and undergo soil microbial biotransformation, it could form PFPeA, PFHpA, PFHxA, 5:3 acid, and 4:3 acid in the environment.

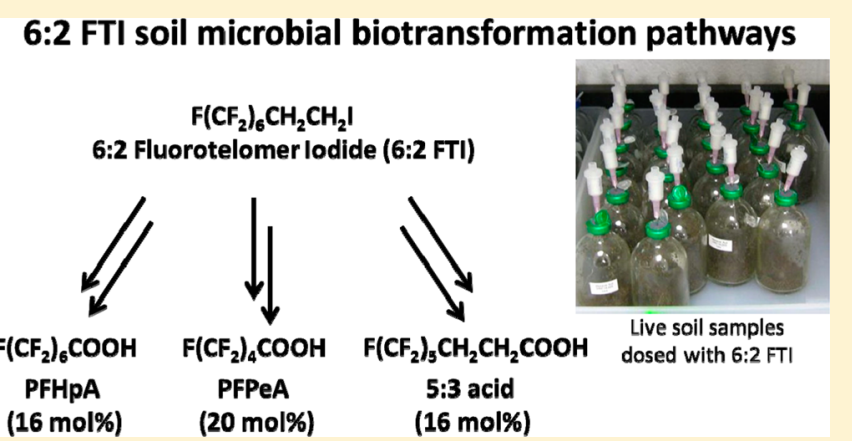

\section{INTRODUCTION}

Perfluorocarboxylates [e.g., perfluorooctanoic acid (PFOA)] and sulfonates [e.g., perfluorooctane sulfonic acid (PFOS)] were detected in various environmental compartments ${ }^{1-4}$ and biological species, including humans, ${ }^{4-7}$ because of their widespread consumer and industrial use and subsequent release to the environment, including surfactants, lubricants, paints, and coatings over the past 60 years. $^{8}$ The toxicity of PFOS and PFOA in laboratory animals and humans was reviewed recently. ${ }^{4}$ Because of their persistence and potential toxicity, these perfluoroalkyl substances (PFASs) have been subjected to increased public scrutiny in recent years. The environmental loading of PFASs is generally related to direct manufacturing emissions and secondary exposure from use and disposal of consumer products, as well as indirect transformation of precursors. ${ }^{9,10}$ Such precursors include perfluoroalkane sulfonyl-based (e.g., $N$-ethyl perfluorooctanesulfonamide) and fluorotelomer-based [e.g., fluorotelomer alcohol (FTOH)] products. $^{9,10}$

Polyfluorinated fluorotelomer iodides (FTIs) are key industrial intermediates used to synthesize FTOHs and other FTOH-based products for consumer and industrial applications. ${ }^{11,12}$ FTOH-based consumer products contained less than
$0.05 \%$ residual 8:2 FTI $\left[\mathrm{F}\left(\mathrm{CF}_{2}\right)_{8} \mathrm{CH}_{2} \mathrm{CH}_{2} \mathrm{I}\right]$ and 6:2 FTI $\left[\mathrm{F}\left(\mathrm{CF}_{2}\right)_{6} \mathrm{CH}_{2} \mathrm{CH}_{2} \mathrm{I}\right],{ }^{13,14}$ which may be subjected to abiotic and microbial biodegradation when the products are disposed to the environment at the end of their life cycle. ${ }^{12,15-17}$

6:2 FTI is the principal industrial raw material used to manufacture 6:2 FTOH and 6:2 FTOH-based products by major global manufacturers. ${ }^{11}$ 6:2 FTI manufacturing sites could be potential sources for $6: 2$ FTI to be released to the environment during production. For example, 6:2 FTI levels reported at a manufacturer site and in the vicinity ranged from 1.4 to $368 \mathrm{ng} \mathrm{m}^{-3}$ air in the atmosphere and $17 \mathrm{ng} \mathrm{kg}^{-1}$ in surface soil, while 8:2 FTI ranged from 1.3 to $1320 \mathrm{ng} \mathrm{m}^{-3}$ and from 145 to $499 \mathrm{ng} \mathrm{kg}^{-1}$, respectively. ${ }^{12} 6: 2$ FTI has a predicted vapor pressure of $386 \mathrm{~Pa}$ and $\log K_{\mathrm{oc}}$ of 5.6, compared to 129 $\mathrm{Pa}$ and 3.6 for 6:2 FTOH, respectively. ${ }^{18}$ 6:2 FTI released to the environment via potential industrial emission may undergo abiotic degradation in the atmosphere and biotransformation in surface soil.

\section{Received: April 24, 2013}

Revised: September 5, 2013

Accepted: September 10, 2013

Published: September 10, 2013 
No information is currently available on 6:2 FTI biotransformation potential in the environment. Therefore, it is not known whether or not 6:2 FTI will be transformed to the same perfluorocarboxylic acids (PFCAs) and polyfluoro carboxylic acids via similar biotransformation pathways as described for 6:2 FTOH $\left[\mathrm{F}\left(\mathrm{CF}_{2}\right)_{6} \mathrm{CH}_{2} \mathrm{CH}_{2} \mathrm{OH}\right] .^{19-21}$ The terminal iodide of the 6:2 FTI molecule is a good leaving group with relatively strong nucleophilicity compared to hydroxyl and other functional groups. ${ }^{22}$ This unique property may facilitate 6:2 FTI conversion via biotransformation pathway(s) otherwise not available to 6:2 FTOH and other 6:2 FTOH-based analogues. Consequentially, 6:2 FTI may be biotransformed by microbes in the environment to form some stable product(s) with higher molar yields compared to 6:2 FTOH and 6:2 FTOH-based analogues.

6:2 FTOH aerobic biotransformation in soil, ${ }^{19}$ sediment, $^{20}$ and activated sludge ${ }^{21}$ generated two types of major transformation products: PFCAs [e.g., perfluorobutanoic acid (PFBA), perfluoropentanoic acid (PFPeA), and perfluorohexanoic acid (PFHxA) $]$ and $x: 3$ acids $\left(\left[\mathrm{F}\left(\mathrm{CF}_{2}\right)_{x} \mathrm{CH}_{2} \mathrm{CH}_{2} \mathrm{COOH}\right.\right.$, where $x=3$, 4, or 5]. Perfluoroheptanoic acid (PFHpA) was not observed in any of these aerobic studies. 6:2 FTOH anaerobic biotransformation in digester sludge formed mostly polyfluorocarboxylic acids and low levels of PFHxA $(\leq 0.4 \mathrm{~mol}$ $\%)^{23}$

Aerobic biotransformation of 6:2 fluorotelomer analogues, such as 6:2 fluorotelomer sulfonate [6:2 FTSA, $\mathrm{F}\left(\mathrm{CF}_{2}\right)_{6} \mathrm{CH}_{2} \mathrm{CH}_{2} \mathrm{SO}_{3}^{-}$] and 6:2 fluorotelomer ethoxylate, in activated sludge or sludge effluent generally followed similar degradation pathways as 6:2 FTOH, which was either bypassed or initially formed and subsequently converted to PFPeA, PFHxA, and 5:3 acid. ${ }^{24,25}$ Aerobic biotransformation of 6:2 fluorotelomer phosphates in activated sludge with inorganic phosphate being removed also formed 6:2 FTOH, PFPeA, PFHxA, and 5:3 acid, as well as $1-1.3 \mathrm{~mol} \% \mathrm{PFHpA}^{26}$ It is not clear whether these low levels of PFHpA observed were from 6:2 fluorotelomer monophosphate [6:2 monoPAP, $\left.\mathrm{F}\left(\mathrm{CF}_{2}\right)_{6} \mathrm{CH}_{2} \mathrm{CH}_{2} \mathrm{H}_{2} \mathrm{PO}_{4}\right]$ and 6:2 fluorotelomer diphosphate [6:2 diPAP, $\left.\left[\mathrm{F}\left(\mathrm{CF}_{2}\right)_{6} \mathrm{CH}_{2} \mathrm{CH}_{2}\right]_{2} \mathrm{HPO}_{4}\right]$ or impurity biodegradation, because no information was presented regarding the purity of the two test materials. ${ }^{26}$ Soil biotransformation of $8: 2$ fluorotelomer stearate monoester ${ }^{27}$ and citrate triester ${ }^{28}$ also generated $0.4-0.9 \%$ PFHpA. PFHpA, along with other PFCAs detected in the environment and biota, may come from direct emission and precursor degradation.

PFHpA ranged from 1.7 to $43 \mathrm{ng} \mathrm{L}^{-1}$ in activated sludge of WWTPs, up to $7.5 \mathrm{ng} \mathrm{g}^{-1}$ in river sediment, and up to $30 \mathrm{ng}$ $\mathrm{L}^{-1}$ in surface water. ${ }^{29} \mathrm{PFHpA}$ in human blood ranged from nondetectable to $0.4 \mathrm{ng} \mathrm{mL}^{-1}$ in U.S. populations surveyed between 1999 and 2011. ${ }^{30}$ Cytotoxicity of PFHpA in a marine bacterium, rat cell lines, and human liver cells ranked between PFHxA and PFOA. ${ }^{31,32}$ The blood elimination half-life is less than 30 days for PFHxA and approximately 1.5-4.5 months for PFHpA in ski-wax workers exposed to high levels of FTOHs via inhalation. ${ }^{33}$

The goals of this study were to investigate 6:2 FTI aerobic soil biotransformation potential, to quantify biotransformation products, and to elucidate 6:2 FTI biotransformation pathways. The outcomes of this study can help discern the sources of poly- and perfluoro carboxylates detected in the environment.

\section{MATERIALS AND METHODS}

Materials. Chemical names, acronyms, and molecular structures of the poly- and perfluoroalkyl substances described in this paper are shown in Table SI-1 of the Supporting Information. 6:2 FTI (purity of 98\%) was obtained from Alfa Aesar (WardHill, MA). All other chemicals mentioned below have $96 \%$ or greater purity as previously described. ${ }^{19}$ 6:2 FTOH, PFBA, PFPeA, PFHxA, and PFHpA were purchased from Sigma-Aldrich (St. Louis, MO). 5:2 ketone $\left[\mathrm{F}\left(\mathrm{CF}_{2}\right)_{5} \mathrm{C}\right.$ $\left.(\mathrm{O}) \mathrm{CH}_{3}\right]$ was obtained from TCI America (Portland, OR). Additional unlabeled fluorinated standards $\{6: 2$ FTCA [F$\left.\left(\mathrm{CF}_{2}\right)_{6} \mathrm{CH}_{2} \mathrm{COOH}\right], 6: 2$ FTUCA $\left[\mathrm{F}\left(\mathrm{CF}_{2}\right)_{5} \mathrm{CF}=\mathrm{CHCOOH}\right.$, 5:2 sFTOH $\left[\mathrm{F}\left(\mathrm{CF}_{2}\right)_{5} \mathrm{CH}(\mathrm{OH}) \mathrm{CH}_{3}\right], 5: 3$ acid, 4:3 acid, 5:3 Uacid $\left[\mathrm{F}\left(\mathrm{CF}_{2}\right)_{5} \mathrm{CH}=\mathrm{CHCOOH}\right]$, and $\alpha-\mathrm{OH} 5: 3$ acid [F$\left.\left.\left(\mathrm{CF}_{2}\right)_{5} \mathrm{CH}_{2} \mathrm{CH}(\mathrm{OH}) \mathrm{COOH}\right]\right\}$ used for quantitative analysis were from DuPont (Wilmington, DE). [1,1,2,2-D;3- $\left.{ }^{13} \mathrm{C}\right] 6: 2$ FTOH $\left[\mathrm{F}\left(\mathrm{CF}_{2}\right)_{5}{ }^{13} \mathrm{CF}_{2} \mathrm{CD}_{2} \mathrm{CD}_{2} \mathrm{OH}\right]$ (DuPont, Wilmington, $\mathrm{DE}$ ) and $\left[1,2-{ }^{13} \mathrm{C}\right]$ PFHxA $\left[\mathrm{F}\left(\mathrm{CF}_{2}\right)_{4}{ }^{13} \mathrm{CF}_{2}{ }^{13} \mathrm{COOH}\right]$ (Wellington Laboratories, Ontario, Canada) were used as quantitation internal standards in liquid chromatography/tandem mass spectrometry (LC/MS/MS) analysis. C18 cartridges (600 mg of sorbent) were purchased from Alltech (Deerfield, IL). Acetonitrile was LC/MS-grade, and all other solvents were high-performance liquid chromatography (HPLC)-grade. Deionized water $(18 \mathrm{M} \Omega)$ for biodegradation studies was generated by a Barnstead E-Pure system.

Experimental System. The Sassafras soil (Ultisol) used to study 6:2 and 8:2 FTOH aerobic biotransformation ${ }^{19,34,35}$ was also selected as the microcosm to study 6:2 FTI aerobic biodegradation. The soil was collected from the same site in an undisturbed forested area for more than 40 years in Newark, DE in March, 2012, was sieved immediately upon collection via a $2 \mathrm{~mm}$ sieve, and was stored at $4{ }^{\circ} \mathrm{C}$ until use. The soil consisted of $52 \%$ sand, $34 \%$ silt, and $14 \%$ clay, with $3.8 \%$ organic matter and $\mathrm{pH}$ of approximately 5.8. The initial gravimetric moisture content of approximately $19 \%$ in live soil and $10 \%$ in sterile soil was adjusted to approximately $50 \%$ of the maximum soil water holding capacity by adding deionized water and equilibrating for 2 days before use.

Crimp-sealed glass serum bottles ( $120 \mathrm{~mL}$ volume) with butyl rubber stoppers were used as the test vessels. Soil was also sterilized by Cobalt-60 $\gamma$-ray irradiation. Triplicate vessels for dosed live soil (live) and sterile-soil negative control (sterile) and duplicate live soil blank matrix (matrix, dosed with carrier solvent only) were individually prepared to cover each sampling time (days 0, 1, 3, 9, 14, 28, 58, and 91). Sample bottles containing $8.3 \mathrm{~g}$ of dry weight equivalent soil were incubated for 2 days before being dosed with 6:2 FTI or pure ethanol. For the live group, $10 \mu \mathrm{L}$ of $6: 2$ FTI stock solution $\left(4.0 \mathrm{mg} \mathrm{mL}^{-1}\right.$ made in pure ethanol) was dosed into each bottle to a final concentration of approximately $4.0 \mu \mathrm{g} \mathrm{g}^{-1}$ of soil $\left(8.4 \mathrm{nmol} \mathrm{g}^{-1}\right.$ of soil). For the live matrix control group, only $10 \mu \mathrm{L}$ of ethanol was dosed into each sample bottle. Prior to adding 6:2 FTI stock solution to sterilized soil samples, triple antibiotics (kanamycin, chloramphenicol, and cycloheximide) were dosed into each bottle to a final concentration of $100 \mathrm{mg} \mathrm{kg}^{-1}$ of dry soil to retard potential microbe growth. After 6:2 FTI or ethanol dosing, the soil in each sample bottle was thoroughly mixed with a metal spatula.

After each test vessel was filled with appropriate test media, each bottle was sealed with a sterilized butyl rubber septum/ aluminum cap. One acetonitrile pre-rinsed $\mathrm{C} 18$ cartridge was 
used as the conduit through an 18-gauge needle pierced through the septum to the headspace for aeration and also for capturing parent compound and potential volatile transformation products. ${ }^{20}$ All bottles were incubated statically in the dark at room temperature $\left(22 \pm 3{ }^{\circ} \mathrm{C}\right)$ prior to sample processing and analysis. The headspace oxygen concentration in each matrix control bottle dosed with only pure ethanol was monitored periodically in situ with a 23-gauge needle oxygen probe (model 905, Quantek Instruments, Grafton, MA) to approximate the $\mathrm{O}_{2}$ content in live soil groups. The headspace of the live and matrix control groups were purged with approximately $3 \mathrm{~L}$ of ambient air when the oxygen content was near or below $10 \%$. The oxygen level at $10 \%$ or above in the headspace of the live soil bottles would ensure an aerobic environment during 6:2 FTI biotransformation because previous work ${ }^{36}$ showed that 8:2 FTOH was biotransformed by activated sludge when the headspace oxygen level was above $4 \%$ in closed bottles.

Sample Pretreatment and Quantitative Analysis. After the headspace was purged with about $3 \mathrm{~L}$ of air through the C18 cartridge, the sample bottles were sacrificed for extraction with acetonitrile. The sample extraction procedures including C18 cartridge elution, septum and soil extractions and EnviCarb cleanup of soil extract to recover soil-bound 5:3 acid in Sassafras soil and instrument quantification measurements were similar to those previously described, ${ }^{19,20,35}$ with slight modifications. Detailed information is given in the Supporting Information. The LC/MS/MS quantitative analysis was performed on a Waters Quattro Micro triple-quadruple mass spectrometry system interfaced with a Waters 2795 HPLC module (Waters, Milford, MA). Electrospray ionization was operated in negative mode, and multiple reaction monitoring (MRM) was used for 6:2 FTOH, 5:2 sFTOH, 5:2 ketone, and all other potential polyfluorinated acid transformation products. An Agilent 6890 GC/5973 MS system (Santa Clara, CA) was also used for quantifying 6:2 FTI in all test vials. Electron impact (EI) ionization positive mode was used, and selective ion monitoring (SIM) helped increase sensitivity. Because no isotope-labeled internal standards were available for FTIs, external standard calibration curves were used to perform quantification.

Structural Elucidation of Biotransformation Products. To identify biotransformation intermediates and establish 6:2 FTI biotransformation pathways, live and matrix groups of test vessels with the incubation period of days $0,3,9,14$, and 28 were also prepared. The microcosm setup in live soil group bottles was similar to the 91 day exposure experiment, except that 12.5 -fold more $6: 2$ FTI ( $500 \mu \mathrm{g}$ in $125 \mu \mathrm{L}$ of pure ethanol) was added to $10 \mathrm{~g}$ of soil inside the glass serum bottle $(50 \mu \mathrm{g}$ $\mathrm{g}^{-1}$ of soil or $105 \mathrm{nmol} \mathrm{g}^{-1}$ of soil) to enhance detection of transformation products with low molar yields. Collection of volatile transformation products accumulated in the headspace of the serum bottles was performed by either solid-phase microextraction (SPME) or trapping of the headspace onto a C18 cartridge. SPME sampling of the headspace was performed with a polydimethylsiloxane (PDMS) fiber equilibrated with the headspace for $40 \mathrm{~min}$, which allowed for a single analysis. SPME sampling was used to maximize the detection potential of volatile transformation products because of high concentration factors and solventless sampling to avoid interfering solvent peaks. Using another set of bottles, the headspace was purged with about $3 \mathrm{~L}$ of ambient air into the C18 cartridge. The C18 cartridge was eluted with $3 \mathrm{~mL}$ of methyl tert-butyl ether (MTBE), which allowed for multiple analysis. The remaining soil in a bottle, after being saturated with deionized water $(\sim 12 \mathrm{~mL})$, was extracted with $10 \mathrm{~mL}$ of MTBE instead of $30 \mathrm{~mL}$ of acetonitrile. Detailed information is summarized in the Supporting Information.

A Waters gas chromatography time-of-flight mass spectrometer equipped with an Agilent 6890N gas chromatograph system (GC-TOF MS) was employed in the full-scan mode $(25-800 \mathrm{amu})$ to detect and elucidate structures of volatile biotransformation products collected with the SPME fibers or present in the MTBE extracts of C18 cartridges. For live and matrix control soil extracts, a LTQ Orbitrap MS (Thermo Fisher Scientific, Inc., Waltham, MA) with electrospray negative ionization was used. Full-scan $(m / z 100-1000)$ mass data with a resolution of 30000 were acquired to identify potential biotransformation products. Mass defect filtration $(\mathrm{m} / z$ 100500 , from -50 to $+10 \mathrm{mDa}$ ) was applied to the data to eliminate the signals that are not pertinent to polyfluorinated transformation products. Molecular structure elucidation was based on accurate mass measurement of deprotonated molecule ions and corresponding product ion spectra. Neat 6:2 FTI used in this study was analyzed on the GC-TOF MS system equipped with a MS detector and a flame ionization detector (FID) (see Table SI-5 of the Supporting Information) to identify the impurities with MS detector and quantify the impurities with FID by calculating the impurity peak area percentage from the FID chromatograms. The putatively identified impurities in the neat 6:2 FTI were examined as potential precursors to PFHpA. Three impurities with unconfirmed chemical structures (because of the lack of authentic standards), which may be potential PFHpA precursors, were found in the neat 6:2 FTI: $\mathrm{F}\left(\mathrm{CF}_{2}\right)_{6} \mathrm{CH}=$ CHI (6:2 FTUI, 0.021\%; see Figure SI-1 of the Supporting Information), $\mathrm{F}\left(\mathrm{CF}_{2}\right)_{6} \mathrm{CH}(\mathrm{OH}) \mathrm{CH}_{2} \mathrm{I}$ (2-OH 6:2 FTI, 0.11\%), and $\mathrm{F}\left(\mathrm{CF}_{2}\right)_{6} \mathrm{CH}_{2} \mathrm{I}(6: 1 \mathrm{FTI}, 0.04 \%)$.

\section{RESULTS AND DISCUSSION}

Experimental System. Figure 1 shows the trend of oxygen levels in the headspace of the live matrix control groups dosed with ethanol. When $10 \mu \mathrm{L}$ of pure ethanol was added to the live sample bottles, the oxygen level decreased to $18.3 \%$ at day 3 and then gradually increased to levels near that in ambient air

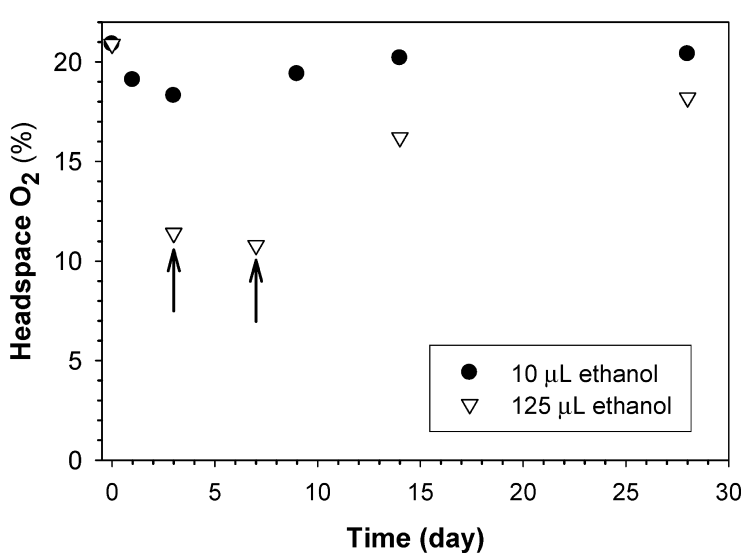

Figure 1. Oxygen levels in the headspace of the live matrix control soil bottles dosed with 10 or $125 \mu \mathrm{L}$ of pure ethanol. The arrows indicate that the headspace was purged with approximately $2 \mathrm{~L}$ of ambient air after $\mathrm{O}_{2}$ measurement. 
by day 14. This suggests that most of the ethanol was mineralized by day 14 and ambient air was in exchange with the headspace through $\mathrm{C} 18$ cartridge conduit. When $125 \mu \mathrm{L}$ of ethanol was added to the live sample bottles, more oxygen was consumed and the oxygen level decreased to $11.4 \%$ by day 3 . After headspace was purged, the oxygen level again decreased to $10.8 \%$ at day 7 and then back to $16-18 \%$ thereafter, suggesting that some remaining ethanol was still consuming oxygen after day 14. For both ethanol levels, the experimental system was aerobic during 6:2 FTI biotransformation.

It is not clear whether the addition of ethanol to the soil experimental system can help enhance 6:2 FTI biotransformation. It is possible that ethanol as an additional organic carbon source in the experimental system may provide metabolic energy and increase microbial populations before it was mineralized. However, it is not known whether increased microbial populations are positively correlated to 6:2 FTI biotransformation potential in soil. Previous work ${ }^{36}$ showed that number 3 carbon of $\left[3-{ }^{14} \mathrm{C}\right] \quad 8: 2$ FTOH [F$\left.\left(\mathrm{CF}_{2}\right)_{7}{ }^{14} \mathrm{CF}_{2} \mathrm{CH}_{2} \mathrm{CH}_{2} \mathrm{OH}\right]$ was mineralized to yield about $12 \%{ }^{14} \mathrm{CO}_{2}$ by activated sludge with periodic addition of ethanol. Because microbial populations in activated sludge may be different from that in soil, further work is needed to determine if the addition of ethanol may promote soil microbes to transform 6:2 FTI and other 6:2 FTOH-related analogues.

Mass Balance. The partitioning of $6: 2$ FTI into the headspace (gas phase) after initial dosing to the soil compartment occurred simultaneously with the aerobic biotransformation processes in the live incubation system (Figure 2). 6:2 FTI soil biotransformation gradually reduced its

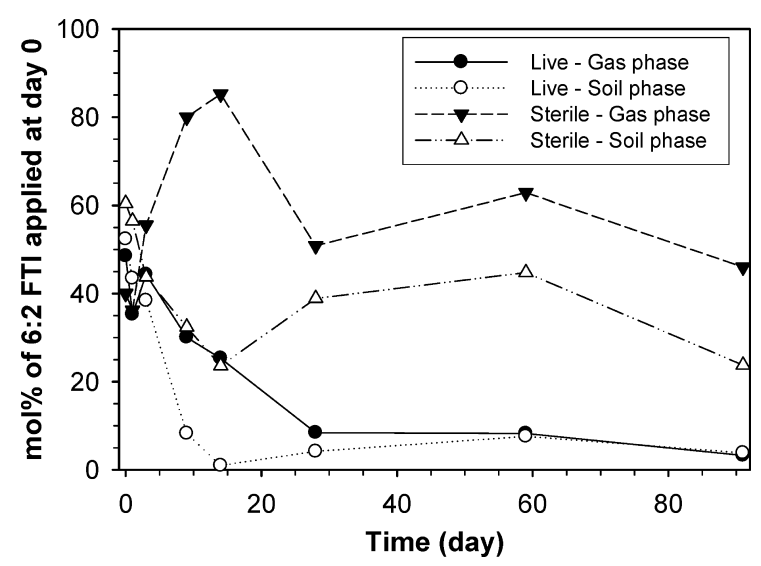

Figure 2. Partitioning of 6:2 FTI into the headspace (gas phase, recovered from $\mathrm{C} 18$ cartridges and septa) and soil phase (recovered from first and second soil extracts) of the live and sterile soil sample bottles.

levels in both the headspace and soil (Figure 2). 6:2 FTI recovered from the gas phase and soil was $7.1 \mathrm{~mol} \%$ of initially applied 6:2 FTI in the live test vessels by day 91 (Figures 2 and $3 A)$. In sterile control vessels, the majority of $6: 2$ FTI was detected in the gas phase from days 3 to 91 (Figure 2). Because 90-112 mol \% of initially applied 6:2 FTI was recovered in sterile control vessels between days 3 and 59 (Figure 3A), this indicates that $\mathrm{C} 18$ cartridges were effective at capturing volatilized 6:2 FTI. C18 cartridge efficiency to capture $6: 2$ FTI may be decreased after 59 days because $70 \mathrm{~mol} \%$ of initially applied 6:2 FTI was recovered in sterile control vessels at day 91 (Figure 3A).
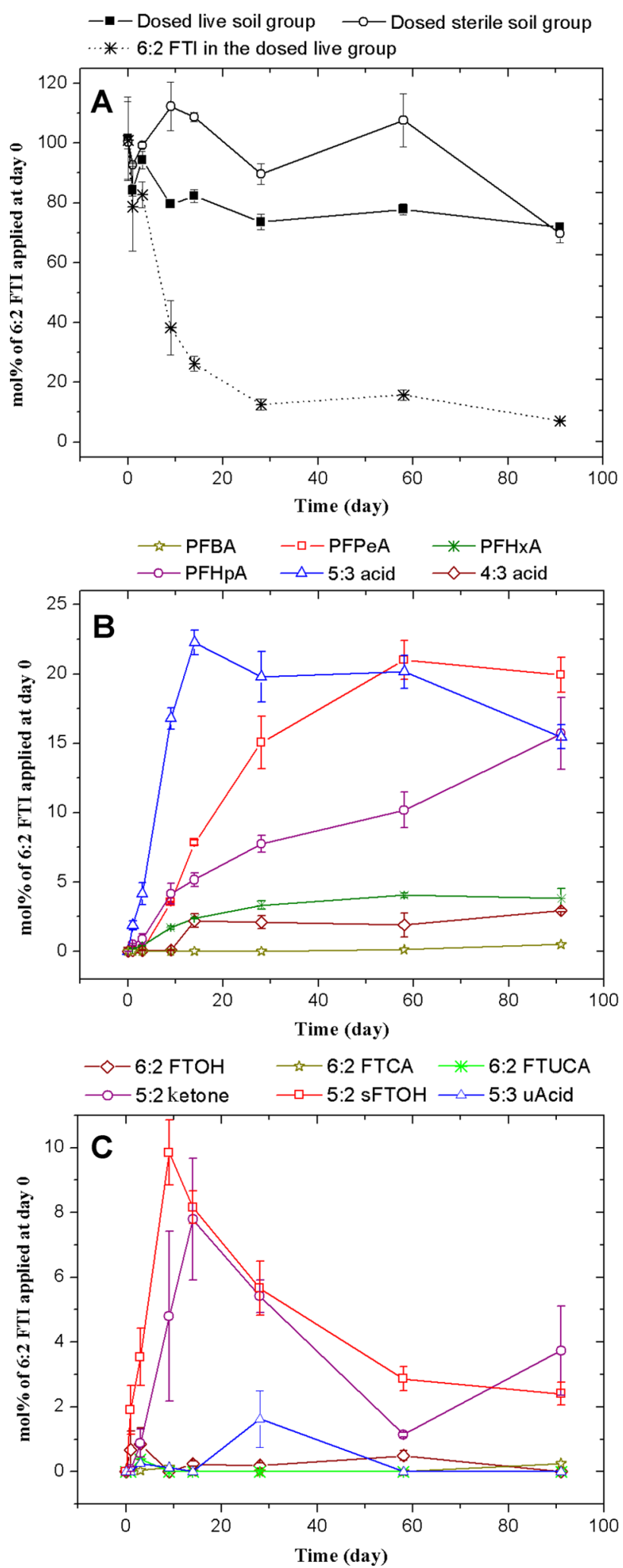

Figure 3. Total molar percentage recovery (mass balance) of 6:2 FTI and quantified transformation products in the incubation system dosed with $40 \mu \mathrm{g}$ of $6: 2 \mathrm{FTI}$ in $10 \mu \mathrm{L}$ of ethanol per sample bottle containing $10 \mathrm{~g}$ of soil. (A) Total mass balance of dosed live soil group $(n=3)$ and sterile soil control $(n=3)$ and time trend of 6:2 FTI in live soil. (B) Molar yields of observed PFCAs (i.e., PFBA, PFPeA, PFHxA, and PFHpA) and $x: 3$ acids (5:3 and 4:3 acids). (C) Molar yields of observed intermediate biotransformation products. 
6:2 FTI primary biotransformation half-life in Sassafras soil was about 4.5 days (Figure 3A), slower than that of 6:2 FTOH in the same type of soil (<2 days). ${ }^{19}$ Total 6:2 FTI recovery ranged from 70 to $112 \mathrm{~mol} \%$ from days 1 to 91 in the sterile control (Figure 3A). Total 6:2 FTI recovery in addition to all quantifiable transformation products ranged from 72 to $94 \mathrm{~mol}$ $\%$ in the live soil (Figure 3A). In a previous study, $\sim 25 \mathrm{~mol} \%$ of initially dosed ${ }^{14} \mathrm{C}$-labeled 6:2 FTOH was converted to nonrecoverable soil-bound residues after 90 days. ${ }^{35}$ The $72 \mathrm{~mol} \%$ total recovery in the live soil at day 91 of this study indicates that most of the major transformation products were accounted for by LC/MS/MS analysis on day 91 soil samples dosed with 6:2 FTI.

PFPeA, PFHpA, and 5:3 Acid Are Three Major Transformation Products during 6:2 FTI Biotransformation. Eight transformation products reported in previous $6: 2$ FTOH aerobic degradation studies ${ }^{19-21}$ were also observed (Figure 3) but absent in the sterile control group, suggesting that the 6:2 FTI biotransformation processes were primarily biological. Among the eight transformation products analyzed for day 0 samples, only PFHxA was detected slightly above the LC/MS/MS detection limit in both live matrix control soil (dosed with $10 \mu \mathrm{L}$ of ethanol) and live soil (dosed with 6:2 FTI) at 4.3 and $5.1 \mathrm{ng} \mathrm{g}^{-1}$ of dry soil, respectively. Odd-number PFPeA and PFHpA were major PFCAs observed in live soil dosed with 6:2 FTI and accounted for 20 and $16 \mathrm{~mol} \%$, respectively, by day 91 (Figure $3 \mathrm{~B}$ and Table 1). In sharp

Table 1. Comparison of Molar Yields of PFCAs and $x: 3$ Acids from 6:2 FTI versus 6:2 FTOH Aerobic Soil

Biotransformation at 3 Months after Initial Dosing with 6:2 FTOH or 6:2 FTI

\begin{tabular}{|c|c|c|}
\hline & \multicolumn{2}{|c|}{$\begin{array}{l}\text { transformation product yields } \\
(\mathrm{mol} \%) \text { in Sassafras soil }\end{array}$} \\
\hline & $\begin{array}{l}\text { 6:2 FTOH } \\
(\text { Liu et al. })^{23}\end{array}$ & $\begin{array}{c}\text { 6:2 FTI } \\
\text { (this study) }\end{array}$ \\
\hline loss of $1 \mathrm{C}$ (one $-\mathrm{CH}_{2}-$ group) & $\begin{array}{l}\text { not detected } \\
\text { (PFHpA) }\end{array}$ & $16($ PFHpA) \\
\hline loss of $2 \mathrm{C}$ (two $-\mathrm{CH}_{2}-$ groups) & 8.1 (PFHxA) & 3.8 (PFHxA) \\
\hline $\begin{array}{l}\text { loss of } 3 \mathrm{C} \text { (one }-\mathrm{CF}_{2}-\text { group and two } \\
-\mathrm{CH}_{2}-\text { groups) }\end{array}$ & 30 (PFPeA) & 20 (PFPeA) \\
\hline $\begin{array}{l}\text { loss of } 4 \mathrm{C} \text { (two }-\mathrm{CF}_{2}-\text { groups and two } \\
-\mathrm{CH}_{2}-\text { groups) }\end{array}$ & 1.8 (PFBA) & $\begin{array}{l}\text { not detected } \\
\quad(\text { PFBA })\end{array}$ \\
\hline \multirow[t]{2}{*}{$x: 3$ acids } & $15(5: 3$ acid $)$ & $16(5: 3$ acid $)$ \\
\hline & $\sim 1(4: 3$ acid $)$ & $3.0(4: 3$ acid $)$ \\
\hline sum of PFCAs and $x: 3$ acids & $56 \%$ & $59 \%$ \\
\hline
\end{tabular}

contrast, PFPeA accounted for $30 \mathrm{~mol} \%$ and no PFHpA was detected in soil dosed with 6:2 FTOH. ${ }^{19}$ PFHpA observed in soil dosed with 6:2 FTI did not originate from impurities of the 6:2 FTI test material, because the potential PFHpA precursors account for less than $0.2 \%$ of the test material. PFHpA identity was confirmed by high-resolution mass spectrometry analysis along with other transformation products (see Figure SI-2 of the Supporting Information). It is worth noting that PFHpA was not detected in soil, sediment, and activated sludge dosed with 6:2 FTOH or 6:2 FTSA $\left[\mathrm{F}\left(\mathrm{CF}_{2}\right) \mathrm{CH}_{2} \mathrm{CH}_{2} \mathrm{SO}_{3}\right],{ }^{19-21,24}$ further confirming that PFHpA did not come from 6:2 FTOH biotransformation. Even-number PFBA was not observed, and PFHxA accounted for $3.8 \mathrm{~mol} \%$ by day 91 (Figure 3B and Table 1), less than half of that in soil dosed with $6: 2 \mathrm{FTOH}^{19}$

On the basis of the current literature, 6:2 FTI seems to be a fluorotelomer substance that can be biotransformed to PFHpA with significant molar yields by microbes in the environment. Other analogues, including 6:2 FTOH itself, were either not converted to PFHpA or with low conversion yields (Table 2 and references therein). Similarly, 8:2 $\mathrm{FTOH}^{34,36,37}$ and its analogues ${ }^{27,28}$ were also not transformed to PFNA by microbes (Table 2), and thus, 8:2 FTOH-based products are unlikely a significant source of PFNA detected in the environment via microbial biotransformation. However, it is possible that 8:2 FTI could be transformed to PFNA via a similar microbial pathway for 6:2 FTI. Future experimental work is needed to confirm this possibility.

5:3 acid reached peak levels at day 14 at $22 \mathrm{~mol} \%$ and then decreased to $16 \mathrm{~mol} \%$ by day 91 (Figure $3 \mathrm{~B}$ and Table 1 ), comparable to the observed 5:3 acid level in soil dosed with $6: 2$ FTOH ${ }^{19}$ and $4: 3$ acid accounted for $3.0 \mathrm{~mol} \%$ at day 91 . The decreased 5:3 acid level after day 14 may reflect increased tendency for 5:3 acid to be bound to soil and was therefore more difficult to recover even with solvent extraction and postprocessing with base extraction and EnviCarb cleanup procedures. $^{20,35}$

Transient polyfluoroalkyl acids, such as 6:2 FTCA, 6:2 FTUCA, and 5:3 Uacid, were detected at low concentrations during 6:2 FTI biotransformation in soil (Figure 3C), likely because of their fast further degradation to downstream biotransformation products, as was observed in 6:2 FTOHdosed soil. ${ }^{19}$ Low levels of $6: 2$ FTOH $(<1 \mathrm{~mol} \%)$ were observed from days 1 to 58 in soil dosed with 6:2 FTI because of 6:2 FTOH subsequent rapid biotransformation. More volatile downstream biotransformation products, 5:2 ketone and 5:2 sFTOH (direct precursors of PFPeA and PFHxA), ${ }^{19}$ peaked between 9 and 14 days with 7.8 and $8.2 \mathrm{~mol} \%$, respectively, and then decreased gradually thereafter to 3.7 and $2.4 \mathrm{~mol} \%$ by day 91 , with the majority of them detected in the headspace. The observed volatile intermediates, PFCAs, and $x: 3$ acids, except PFHpA, were also observed in 6:2 FTOHdosed soil, sediment, and activated sludge, ${ }^{19-21}$ suggesting that 6:2 FTI aerobic degradation processes at least shared some of the biotransformation pathways with 6:2 FTOH.

Even though an individual PFCA molar yields may be variable in soil dosed with 6:2 FTI in comparison to those of 6:2 FTOH, the total molar yields of PFCAs and $x: 3$ acids are very similar at $59 \mathrm{~mol} \%$ in soil dosed with $6: 2$ FTI versus 56 $\mathrm{mol} \%$ in aerobic soil dosed with 6:2 FTOH (Table 1). Thus, aerobic soil biotransformation of 6:2 FTI or 6:2 FTOH may contribute almost equally to the environmental load of total PFCAs and $x: 3$ acids if either was released to surface soil.

6:2 FTI Biotransformation Pathways. On the basis of observed transient intermediates and major PFCAs and $x: 3$ acids detected by LC/MS/MS and high-resolution mass spectrometry analysis, we postulate that 6:2 FTI biotransformation in soil mainly occurred via two major routes: one via $6: 2$ FTUI $\left[\mathrm{F}\left(\mathrm{CF}_{2}\right)_{6} \mathrm{CH}=\mathrm{CH}_{2} \mathrm{I}\right]$ to $\mathrm{PFHpA}$ and the other via $6: 2$ FTOH to PFPeA, PFHxA, and $x: 3$ acids (Figure 4 ).

The proposed pathway from 6:2 FTUI to PFHpA was not verified with authentic standards, which are not currently available. The possible pathway from 6:2 FTUI to PFHpA was based on observed transformation steps, which also occurred to 6:2 FTOH, 8:2 FTOH, and related transformation products, including 5:3 acid, 5:3 $\mathrm{U}$ acid, $\alpha-\mathrm{OH} 5: 3$ acid, $^{19-21,34,36,38}$ as well as QSAR predictions using the Pathway Prediction System $^{39}$ and Catabol. ${ }^{40}$ Both QSAR tools are based on known enzymatic reactions and biochemical processes of organic chemicals. For the possible 6:2 FTUI route leading 
Table 2. PFHpA $\left[\mathrm{F}\left(\mathrm{CF}_{2}\right)_{6} \mathrm{COOH}\right]$ Molar Yields from Biotransformation of 6:2 FTOH and 6:2 and 8:2 FTOH Analogues and PFNA $\left[\mathrm{F}\left(\mathrm{CF}_{2}\right)_{8} \mathrm{COOH}\right]$ Molar Yields from Biotransformation of 8:2 FTOH and 8:2 FTOH Analogues in Various Environmental Matrices

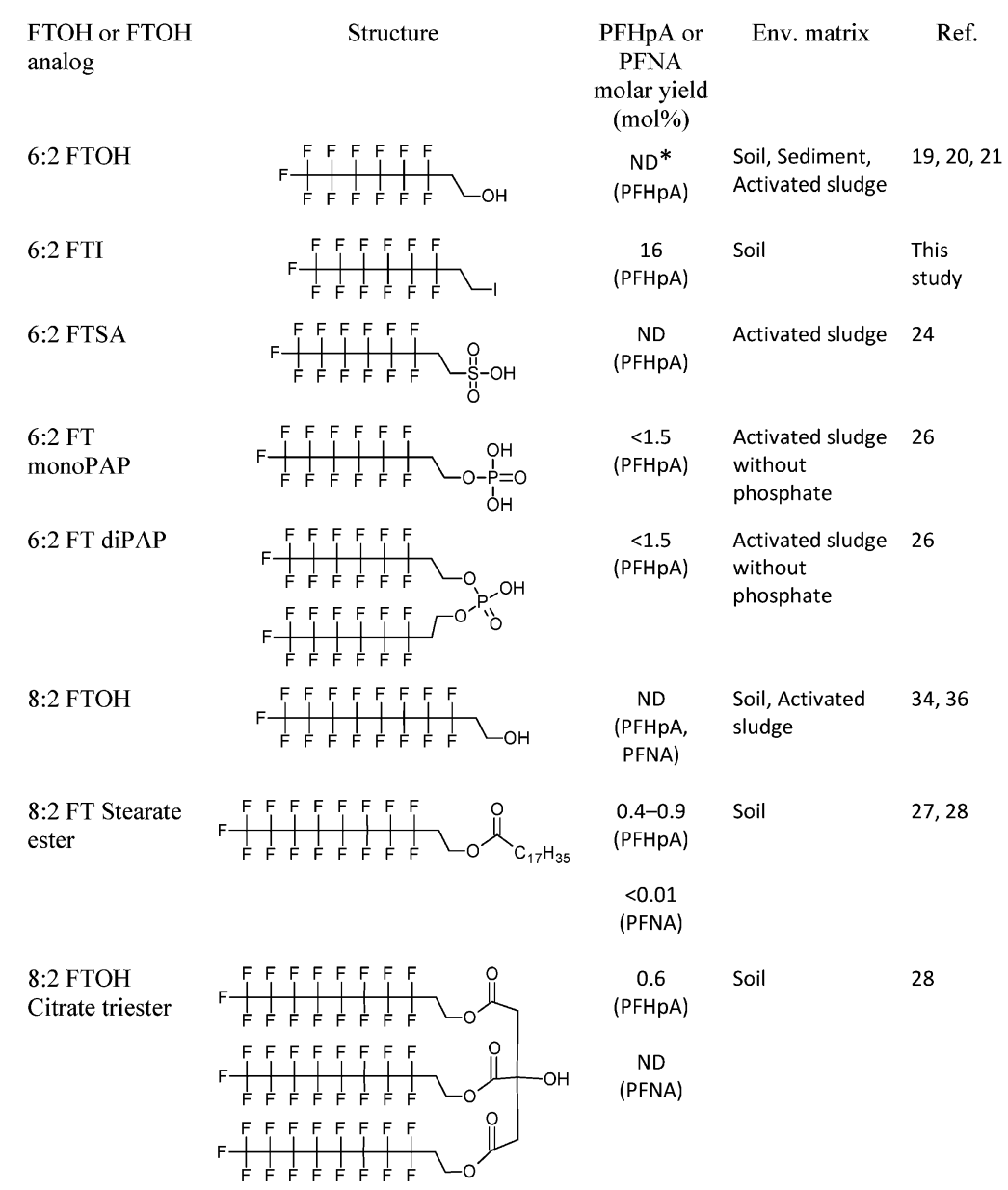

*Not detected.

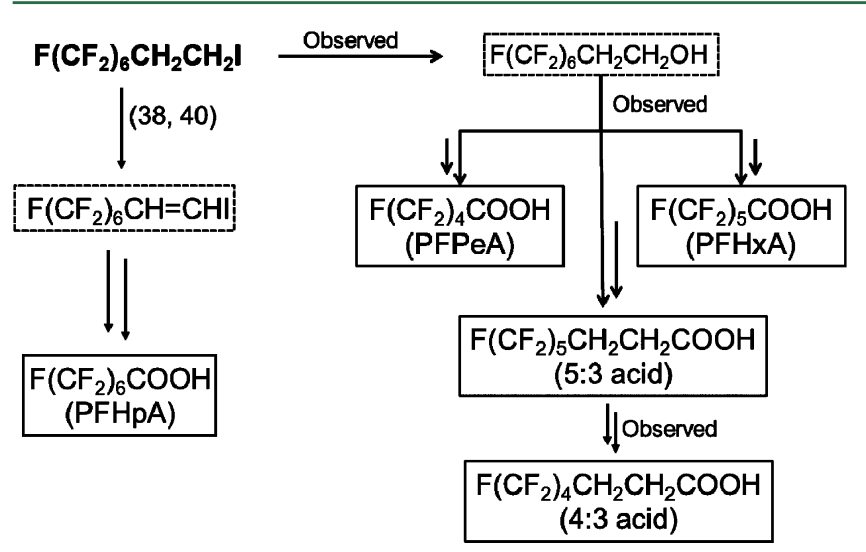

Figure 4. Proposed 6:2 FTI aerobic biotransformation pathways. The putative pathway from 6:2 FTUI to PFHpA was not verified because of the lack of authentic standards. The numeric numbers inside the parentheses are references cited in this study. The dashed rectangular boxes represent the two intermediates leading to two different biotransformation pathways, and the solid rectangular boxes represent major biotransformation products. The solid double arrows indicate multiple reaction steps.

to PFHpA (Figure 4), 6:2 FTI could be initially dehydrogenated via a dehydrogenation (desaturation) reaction similar to that reported for 5:3 acid ${ }^{38}$ to form 6:2 FTUI. The terminal iodide of 6:2 FTI would render the $\mathrm{C} 1$ carbon (the carbon bonding to iodide) polarized, similar to the polarized carbonyl carbon of 5:3 acid, allowing the dehydrogenation reaction to occur. Quantitative analysis of 6:2 FTUI in soil samples dosed with 6:2 FTI was hampered by its presence as a low-level impurity $(0.021 \%)$ in 6:2 FTI starting material and also its facile transformation to downstream transformation products.

6:2 FTUI putative EI mass spectra were acquired by GCTOF MS analysis of 6:2 FTI starting material impurities and a day 3 soil sample (see Figure SI-3 of the Supporting Information). 6:2 FTUI levels in the headspace captured by SPME fibers or C18 cartridges were less than $36 \mathrm{ng}$ in day 328 soil samples dosed with $500 \mu \mathrm{g}$ of 6:2 FTI per sample (see Figure SI-4 of the Supporting Information), which contained approximately $105 \mathrm{ng}(500 \mu \mathrm{g} \times 0.021 \%)$ of $6: 2$ FTUI as impurity. This suggests that 6:2 FTUI, if ever formed from $6: 2$ FTI, was rapidly transformed to other downstream transformation products. Similarly, when 6:2 FTUCA was added to activated sludge, its possible intermediates leading to 5:2 ketone were also not observed by high-resolution mass spectrometry analysis. ${ }^{38} \mathrm{We}$ are in the process of acquiring 6:2 FTUI standard to be dosed to soil samples to see if it can be converted to PFHpA by soil microbial enzymes via five possible enzymatic steps described in Figure SI-5 of the Supporting Information. 
For the 6:2 FTOH route (Figure 4), the terminal iodide on 6:2 FTI was first hydrolytically substituted with a hydroxyl group to form 6:2 FTOH, as observed by LC/MS/MS analysis. 6:2 FTOH was rapidly biotransformed to downstream major products, such as PFPeA, PFHxA, and $x: 3$ acids, as also occurred in soil dosed with $6: 2 \mathrm{FTOH}$ as the starting material. ${ }^{19}$ 6:2 FTOH soil biotransformation pathways were described in detail ${ }^{19}$ and were later confirmed by pure Pseudomonas bacterial culture. ${ }^{41}$ In this study, PFPeA and 5:3 acid were observed as two abundant products, consistent with a previous soil biotransformation study with $6: 2 \mathrm{FTOH}^{19}$ and further confirming that the $6: 2 \mathrm{FTOH}$ route was operational in soil dosed with 6:2 FTI. However, PFBA was not observed, and the PFHxA level was less than half of that in soil dosed with 6:2 FTOH (Table 1), suggesting that part of the 6:2 FTOH route may have been diverted toward the putative $6: 2$ FTUI route in soil dosed with 6:2 FTI, producing significant amounts of PFHpA.

Environmental Implications. The experimental results in this study showed that 6:2 FTI underwent aerobic soil biotransformation processes to form PFPeA, PFHxA, 5:3 acid, and 4:3 acid via 6:2 FTOH pathways. In addition, 6:2 FTI biotransformation in soil also formed significant PFHpA via a putative 6:2 FTUI pathway. PFPeA, PFHpA, and PFHxA detected in the environment could come from direct PFCA emission or through precursor abiotic and microbial biodegradation. Because global 6:2 FTI production is likely to continue, potential industrial emissions of $6: 2$ FTI from manufacturing could contribute to the environmental loading of PFPeA, PFHpA, and PFHxA, although to what extent is still yet to be determined.

\section{ASSOCIATED CONTENT}

\section{S Supporting Information}

Sample pretreatment and quantitative analysis, structural elucidation of biotransformation products, putative 6:2 FTI biotransformation pathway to $\mathrm{PFHpA}$, chemical names, acronyms, and molecular structures of the polyfluorinated chemicals analyzed or described in this paper (Table SI-1), instrumental method parameters and method quantification limits in the LC/MS/MS quantitative analysis (Table SI-2), instrumental method parameters and method quantification limits in the GC/MS quantitative analysis (Table SI-3), instrumental method parameters of GC-TOF MS for the structural elucidation of biotransformation products (Table SI4), instrumental method parameters of LC-LTQ Orbitrap MS for the structural elucidation of biotransformation products (Table SI-5), impurity profiles of 6:2 FTI used for testing (Figure SI-1), observed transformation products in MTBE extracts from day 1-28 soil samples (Figure SI-2), EI spectrum of 6:2 FTUI (Figure SI-3), extracted ion chromatograms of 6:2 FTUI in day 0-28 samples (Figure SI-4), putative 6:2 FTI biotransformation pathway to PFHpA (Figure SI-5), and references. This material is available free of charge via the Internet at http://pubs.acs.org.

\section{AUTHOR INFORMATION}

\section{Corresponding Authors}

*Telephone: 8610-62849334. Fax: 8610-62849179. E-mail: gbjiang@rcees.ac.cn.

*Telephone: +1-302-366-6665. Fax: +1-302-366-6602. E-mail: ning.wang@usa.dupont.com.

\section{Notes}

The authors declare the following competing financial interest(s): five co-authors are employees of E. I. duPont de Nemours and Company, Inc., a manufacturer of 6:2 FTI.

\section{ACKNOWLEDGMENTS}

We thank the National Natural Science Foundation of China (21207140 and 20890111), the National Basic Research Program of China (2009CB421603), and Chinese Academy of Sciences Grants YSW2013B01 and GJHZ1202 for joint financial support of the authors in the Chinese Academy of Sciences.

\section{REFERENCES}

(1) Piekarz, A. M.; Primbs, T.; Field, J. A.; Barofsky, D. F.; Simonich, S. Semivolatile fluorinated organic compounds in Asian and western U.S. air masses. Environ. Sci. Technol. 2007, 41 (24), 8248-8255.

(2) Ahrens, L. Polyfluoroalkyl compounds in the aquatic environment: A review of their occurrence and fate. J. Environ. Monit. 2011, 13 (1), 20-31.

(3) Haug, L. S.; Huber, S.; Schlabach, M.; Becher, G.; Thomsen, C. Investigation on per- and polyfluorinated compounds in paired samples of house dust and indoor air from Norwegian homes. Environ. Sci. Technol. 2011, 45 (19), 7991-7998.

(4) Lau, C. Perfluorinated compounds. EXS 2012, 101, 47-86.

(5) Kärrman, A.; Ericson, I.; Bavel, B. V.; Darnerud, P. O.; Aune, M.; Glynn, A.; Lignell, S.; Lindström, G. Exposure of perfluorinated chemicals through lactation: Levels of matched human milk and serum and a temporal trend, 1996-2004, in Sweden. Environ. Health Perspect. 2007, 115 (2), 226-230.

(6) Kannan, K.; Corsolini, S.; Falandysz, J.; Oehme, G.; Focardi, S.; Giesy, J. P. Perfluorooctanesulfonate and related fluorinated hydrocarbons in marine mammals, fishes, and birds from coasts of the Baltic and the Mediterranean Seas. Environ. Sci. Technol. 2002, 36 (15), 3210-3216.

(7) Tomy, G. T.; Budakowski, W.; Halldorson, T.; Helm, P. A.; Stern, G. A.; Friesen, K.; Pepper, K.; Tittlemier, S. A.; Fisk, A. T. Fluorinated organic compounds in an eastern Arctic marine food web. Environ. Sci. Technol. 2004, 38 (24), 6475-6481.

(8) Buck, R. C.; Franklin, J.; Berger, U.; Conder, J. M.; Cousins, I. T.; Voogt, P.; Jensen, A. A.; Kannan, K.; Mabury, S. A.; Leeuwen, S. P. J. Perfluoroalkyl and polyfluoroalkyl substances in the environment: Terminology, classification, and origins. Integr. Environ. Assess. Manage. 2011, 7 (4), 513-541.

(9) Prevedouros, K.; Cousins, I. T.; Buck, R. C.; Korzeniowski, S. H. Source, fate and transport of perfluorocarboxylates. Environ. Sci. Technol. 2006, 40 (1), 32-44.

(10) Ritter, S. Y. Fluorochemicals go short. Chem. Eng. News 2010, 88 (5), 12-17.

(11) Kissa, E. Fluorinated Surfactants and Repellents, 2nd ed.; Marcel Dekker, Inc: New York, 2001.

(12) Ruan, T.; Wang, Y. W.; Wang, T.; Zhang, Q. H.; Ding, L.; Liu, J. Y.; Wang, C.; Qu, G. B.; Jiang, G. B. Presence and partitioning behavior of polyfluorinated iodine alkanes in environmental matrices around a fluorochemical manufacturing plant: Another possible source for perfluorianted carboxylic acids? Environ. Sci. Technol. 2010, 44 (15), 5755-5761.

(13) Russell, M. H.; Berti, W. R.; Szostek, B.; Buck, R. C. Investigation of the biodegradation potential of a fluoroacrylate polymer product in aerobic soils. Environ. Sci. Technol. 2008, 42, 800807.

(14) Russell, M. H.; Berti, W. R.; Szostek, B.; Wang, N.; Buck, R. C. Evaluation of PFO formation from the biodegradation of a fluorotelomer-based urethane polymer product in aerobic soils. Polym. Degrad. Stab. 2009, 95, 79-85.

(15) Young, C. J.; Hurley, M. D.; Wallinton, T. J.; Mabury, S. A. Atomspheric chemistry of 4:2 iodidefluorotelomer iodide ( $n$ - 
$\left.\mathrm{C}_{4} \mathrm{~F}_{9} \mathrm{CH}_{2} \mathrm{CH}_{2} \mathrm{I}\right)$ : Kinetics and products of photolysis and reaction with $\mathrm{OH}$ radicals and $\mathrm{Cl}$ atoms. J. Phys. Chem. A 2008, 112 (51), 1354213548 .

(16) Ruan, T.; Wang, Y. W.; Zhang, Q. H.; Ding, L.; Wang, P.; Qu, G. B.; Wang, C.; Wang, T.; Jiang, G. B. Trace determination of airborne polyfluorinated iodine alkanes using multisorbent thermal desorption/gas chromatography/high resolution mass spectrometry. J. Chromatogr., A 2010, 1217 (26), 4439-4447.

(17) Wang, C.; Wang, T.; Liu, W.; Ruan, T.; Zhou, Q. F.; Liu, J. Y.; Zhang, A. Q.; Zhao, B.; Jiang, G. B. The in vitro estrogenic activities of polyfluorinated iodine alkanes. Environ. Health Perspect. 2012, 120 (1), $119-125$.

(18) United States Environmental Protection Agency (U.S. EPA). Exposure Assessment Tools and Models, Estimation Program Interface (EPI) Suite, Version 4.1; Exposure Assessment Branch, U.S. EPA: Washington, D.C., 2011.

(19) Liu, J. X.; Wang, N.; Szostek, B.; Buck, R. C.; Panciroli, P. K.; Folsom, P. W.; Sulecki, L. M.; Bellin, C. A. 6-2 fluorotelomer alcohol aerobic biodegradation in soil and mixed bacterial culture. Chemosphere 2010, 78 (4), 437-444.

(20) Zhao, L.; Folsom, P. W.; Wolstenholme, B. W.; Sun, H.; Wang, N.; Buck, R. C. 6:2 fluorotelomer alcohol biotransformation in an aerobic river sediment system. Chemosphere 2012, 90 (2), 203-209.

(21) Zhao, L.; McCausland, P. K.; Folsom, P. W.; Wolstenholme, B. W.; Sun, H.; Wang, N.; Buck, R. C. 6:2 fluorotelomer alcohol aerobic biotransformation in activated sludge from two domestic wastewater treatment plants. Chemosphere 2013, 92, 464-470.

(22) Vollhardt, K. P. C. Organic Chemistry; W.H. Freeman and Company: New York, 1987.

(23) Zhang, S.; Szostek, B.; McCausland, P. K.; Wolstenholme, B. W.; Lu, X.; Wang, N.; Buck, R. C. 6:2 and 8:2 fluorotelomer alcohol anaerobic biotransformation in digester sludge from a WWTP under methanogenic conditions. Environ. Sci. Technol. 2013, 47, 4227-4235.

(24) Wang, N.; Liu, J.; Buck, R. C.; Korzeniowski, S. H.; Wolstenholme, B. W.; Folsom, P. W.; Sulecki, L. M. 6:2 fluorotelomer sulfonate aerobic biotransformation in activated sludge of waste water treatment plants. Chemosphere 2011, 82 (6), 853-858.

(25) Frömel, T.; Knepper, T. P. Fluorotelomer ethoxylates: Sources of highly fluorinated environmental contaminants part I: Biotransformation. Chemosphere 2010, 80 (11), 1387-1392.

(26) Lee, H.; D'eon, J.; Mabury, S. A. Biodegradation of polyfluoroalkyl phosphates as a source of perfluorinated acids to the environment. Environ. Sci. Technol. 2010, 44 (9), 3305-3310.

(27) Dasu, K.; Liu, J. X.; Lee, L. S. Aerobic soil biodegradation of 8:2 fluototelomer stearate monoester. Environ. Sci. Technol. 2012, 46 (7), 3831-3836.

(28) Dasu, K.; Lee, L. S.; Turco, R. F.; Nies, L. F. Aerobic biodegradation of 8:2 fluorotelomer stearate monoester and 8:2 fluorotelomer citrate triester in forest soil. Chemosphere 2013, 91 (3), 399-405.

(29) Llorca, M.; Perez, F.; Farre, M.; Pico, Y.; Barcelo, D. Perfluorinated compounds' analysis, environmental fate and occurrence: The Llobregat River as case study. Handb. Environ. Chem. 2012, 21, 193-238.

(30) United States Centers for Disease Control and Prevention (CDC). Fourth National Report on Human Exposure to Environmental Chemicals, Updated Tables; CDC: Atlanta, GA, March 2013.

(31) Mulkiewicz, E.; Jastorff, B.; Składanowski, A. C.; Kleszczynski, K.; Stepnowski, P. Evaluation of the acute toxicity of perfluorinated carboxylic acids using eukaryotic cell lines, bacteria and enzymatic assays. Environ. Toxicol. Pharmacol. 2007, 23, 279-285.

(32) Buhrke, T.; Kibellus, A.; Lampen, A. In vitro toxicological characterization of perfluorinated carboxylic acids with different carbon chain lengths. Toxicol. Lett. 2013, 218, 97-104.

(33) Nilsson, H.; Kärrman, A.; Rotander, A.; van Bavel, B.; Lindström, G.; Westberg, H. Biotransformation of fluorotelomer compound to perfluorocarboxylates in humans. Environ. Int. 2013, 51, $8-12$.
(34) Wang, N.; Szostek, B.; Buck, R. C.; Folsom, P. W.; Sulecki, L. M.; Gannon, J. T. 8-2 fluorotelomer alcohol aerobic soil biodegradation: Pathways, metabolites, and metabolite yields. Chemosphere 2009, 75 (8), 1089-1096.

(35) Liu, J. X.; Wang, N.; Buck, R. C.; Wolstenholme, B. W.; Folsom, P. W.; Sulecki, L. M.; Bellin, C. A. Aerobic biodegradation of $\left[{ }^{14} \mathrm{C}\right] 6: 2$ fluorotelomer alcohol in a flow-through soil incubation system. Chemosphere 2010, 80 (7), 716-723.

(36) Wang, N.; Szostek, B.; Buck, R. C.; Flosom, P. W.; Sulecki, L. M.; Capka, V.; Berti, W. R.; Gannon, J. T. Fluorotelomer alcohol biodegradation-Direct evidence that perfluorinated carbon chains breakdown. Environ. Sci. Technol. 2005, 39 (19), 7516-7528.

(37) Wang, N.; Szostek, B.; Folsom, P. W.; Sulecki, L. M.; Capka, V.; Buck, R. C.; Berti, W. R.; Gannon, J. T. Aerobic biotransformation of ${ }^{14}$ C-labeled $8-2$ telomer $B$ alcohol by activated sludge from a domestic sewage treatment plant. Environ. Sci. Technol. 2005, 39 (2), 531-538.

(38) Wang, N.; Buck, R. C.; Szostek, B.; Sulecki, L. M.; Wolsternholme, B. W. 5:3 polyfluorinated acid aerobic biotransformation in activated sludge via novel "one-carbon" removal pathways. Chemosphere 2012, 87 (5), 527-534.

(39) Ellis, L. B. M.; Gao, J.; Fenner, K.; Wackett, L. P. The University of Minnesota pathway prediction system: Predicting metabolic logic. Nucleic Acids Res. 2008, 36 (2), W427-W432.

(40) Jaworska, J.; Dimitrov, S.; Nikolova, N.; Mekenyan, O. Probabilistic assessment of biodegradability based on metabolic pathways: catabol system. SAR QSAR Environ. Res. 2002, 13 (2), 307-323.

(41) Kim, M. H.; Wang, N.; McDonald, T.; Chu, K. H. Biodefluorination and biotransformation of fluorotelomer alcohols by two alkane degrading Pseudomonas strains. Biotechnol. Bioeng. 2012, 109 (12), 3041-3047. 